\title{
Analysis of Primordia and Fruiting Forming Days on using Different Sterilization Techniques of Straw and its Effect on Yield of Blue Oyster Mushroom
}

\author{
K.C. Shreejana, Kabita Kurunjư ${ }^{1}$, Ronika Thapa, Shirish Ghimire, Pradeep Shrestha ${ }^{1}$ \\ Department of Microbiology, \\ Institute of Agriculture and Animal Science, Gokuleshwor College, Baitadi, Nepal.
}

Received: September 2021

Accepted: February 2022

\begin{abstract}
Background: Mushroom is a typical fungi having spore bearing fruiting bodies without chlorophyll in them. Due to its high nutritive and medicinal value, it is being popular among the public.

Methods: The research was conducted in laboratory condition of Mahendra Gram Secondary School, Bhaktapur; under control environmental condition to evaluate primordial formation and yield analysis of oyster mushroom Pleurotus florida using different sterilization techniques from March to July 2020.

Result: Earlier primordial formation was visualized in chemical method and higher yield was obtained from steaming method of sterilization. However, boiling method showed harsh result for all parameters as primordial formation, fruiting and yield. But still number of researches should be conducted for the exact evaluation of the yield performance.
\end{abstract}

Key words: Fruiting, Pleurotus florida, Primordia, Sterilization, Yield.

\section{INTRODUCTION}

Mushroom is a fleshy, conspicuous umbrella shaped fruiting body arising from a group of mycelium buried in a substratum. It falls under the order Agaricales and phylum Basidiomycota with sub division Basidiomycotina while few may also lies on Ascomycotina. Even though there is no scientific distinction between sporophores and toadstool, sporophores is considered as edible form of mushroom and toadstools as poisonous mushroom. In a very conservative thoughts mushroom is only considered as edible component regardless of their lethal species also. Mushroom have unique fungal characteristics (Song 2004). Mushrooms, one kind of edible fungi, emanates under the genus and class Pleurotus and Basidiomycetes respectively (Mondal SR 2010). According to (Chang 1992) mushroom contain of about $30-40 \%$ protein with all essential amino acids. Since mushroom doesn't contain cholesterol in them it can be consumed to reduce body weight as well. Mushrooms area than any others crops (Gupta 1986). Mushroom are also found to be helpful to reduce cholesterol in the serum and hypertension (Mori 1986). Ganoderma lucidum is widely well known for its medicinal purposes. Similarly, Sitake and Mitake mushroom are also globally used as source of medicine (Willard 1990). Mushrooms are oftenallied with well-being and repercussion, endurance, perception and pleasure (Stamets 1990). Even though of its multiple uses for the production of large scale quantity and for profit basis close consideration, capability, experiences and skill is essential (Carluccio 1989).

Oyster mushroom (Pleurotus ostreatus) is considered as one of the edible mushroom and it have exceptionalsavor and flavor. Recently, its importance and nourishing value along with its medicinal value has also been identified and widely realized for the balance human diet. There are millions of mushroom identified and some of the species of oyster mushroom are: Pleurotus ostreatus, Pleurotus corticatus Pleurotus florida, Pleurotus eugrammus, Pleurotus salignus, Pleurotus nebrodensis, Pleurotus spodoleucus, Pleurotus flabellatus, Pleurotus columbinus, Pleurotus ostreatoroseus, Pleurotus pulmonarius and subspices are Pleurotus sajorcaju, Pleurotus opuntiae, Pleurotus populinus, rhodophyllus, Pleurotus ulmarius, Pleurotus djamor, Pleurotus eryngii, Pleurotus smithii, Pleurotus cystidiosus, Pleurotus salmoneostrsmineus, Pleurotus calyptratus, Pleurotus dryinus, Pleurotus purpureo-olivaceus, Pleurotus cornucopiae, Pleurotus sapidus and Pleurotus tuber-regiu (Nadir HA 2016). Among the above listed mushroom varieties Pleurotus ostreatus is being widely cultivated as they grow easily in the ecologically sound environment (Kong 2004). (Randive 2012) gave the scientific classification of oyster mushroom as:

Kingdom - Fungi

Phylum - Basidiomycota

Class - Agaricomycetes

${ }^{*}$ Corresponding author's E-mail: sreezaa20@gmail.com

${ }^{1}$ Department of Microbiology, Institute of Agriculture and Animal Science Gokuleshwor, Tribhuvan University. 
Order - Agaricales

Family - Pleurotaceae

Genus - Pleurotus

Species - Pleurotus ostreatus

\section{MATERIALS AND METHODS}

The research was conducted at Mahendra Gram Secondary School located at Chagunarayan municipality- 08, Sudal, Bhaktapur of Bagmati Province at Longitude: E $85^{\circ}$ 28.883' and Latitude: $27.678561^{\circ}$. It was carried in CRD condition from $12^{\text {th }}$ March to July 2020 . Three different sterilization techniques were used i.e. Boiling, Steaming and Chemical methods and days of primordial formation, fruiting and total yield obtained from each sterilization technique was recorded.

\section{Agro meteorological features}

The research room was artificially maintained the following temperature and relative humidity and $\mathrm{p}^{\mathrm{H}}$ Table 1.

\section{Experimental setup}

The experiment procedure was arranged in RCBD design with 3 treatments and three replications. Total of 9 treatments of Blue oyster mushroom studied as a indicator the yield estimation Table 1.

\section{Spawn source}

The wheat grain spawn of Pleurotus ostreatus was available in commercially mushroom growing area and they were acquired from Mushroom Seed Nepal and Research Center Pvt. Ltd. positioned at Madhyapur Thimi, Bhaktapur.
Table 1: Temperature relative humidity and $\mathrm{P}^{\mathrm{H}}$ maintained during the research.

\begin{tabular}{lcc}
\hline Parameter & Primordia formation & Fruiting body \\
\hline Temperature ${ }^{\circ} \mathrm{C}$ & $15-18$ & $21-28$ \\
$\mathrm{RH} \%$ & $76-80$ & $80-90$ \\
$\mathrm{p}^{\mathrm{H}}$ & 6.5 & 6.5 \\
\hline
\end{tabular}

Hygrometer was used to record the relative humidity and temperature while digital $\mathrm{P}^{\mathrm{H}}$ meter was used to record the $\mathrm{p}^{\mathrm{H}}$.

Table 2: Activities during the research period.

\begin{tabular}{ll}
\hline Date & Activities done \\
\hline $12 / 03 / 2020$ & Straw cleaning \\
$13 / 03 / 2020$ & Bag filling for boiling method \\
$16 / 03 / 2020$ & Straw preparation by hot water steaming \\
$17 / 03 / 2020$ & Excess water drain and bag filling \\
$03 / 04 / 2020$ & Mycelium spreading analysis straw preparation by \\
& chemical method bag filling after 16 hrs. \\
$09 / 04 / 2020$ & Primordial formation and Plastic cutting \\
$11 / 04 / 2020$ & Harvesting from steam method \\
$15 / 04 / 2020$ & Light irrigation \\
$16 / 04 / 2020$ & Plastic cutting for chemical method \\
$01 / 05 / 2020$ & Harvesting of chemical method \\
$15 / 05 / 2020$ & Harvesting of boiling method \\
$29 / 05 / 2020$ & Harvesting \\
$10 / 06 / 2020$ & Harvesting \\
$25 / 06 / 2020$ & Harvesting \\
$08 / 07 / 2020$ & Harvesting \\
$20 / 07 / 2020$ & Final harvesting
\end{tabular}

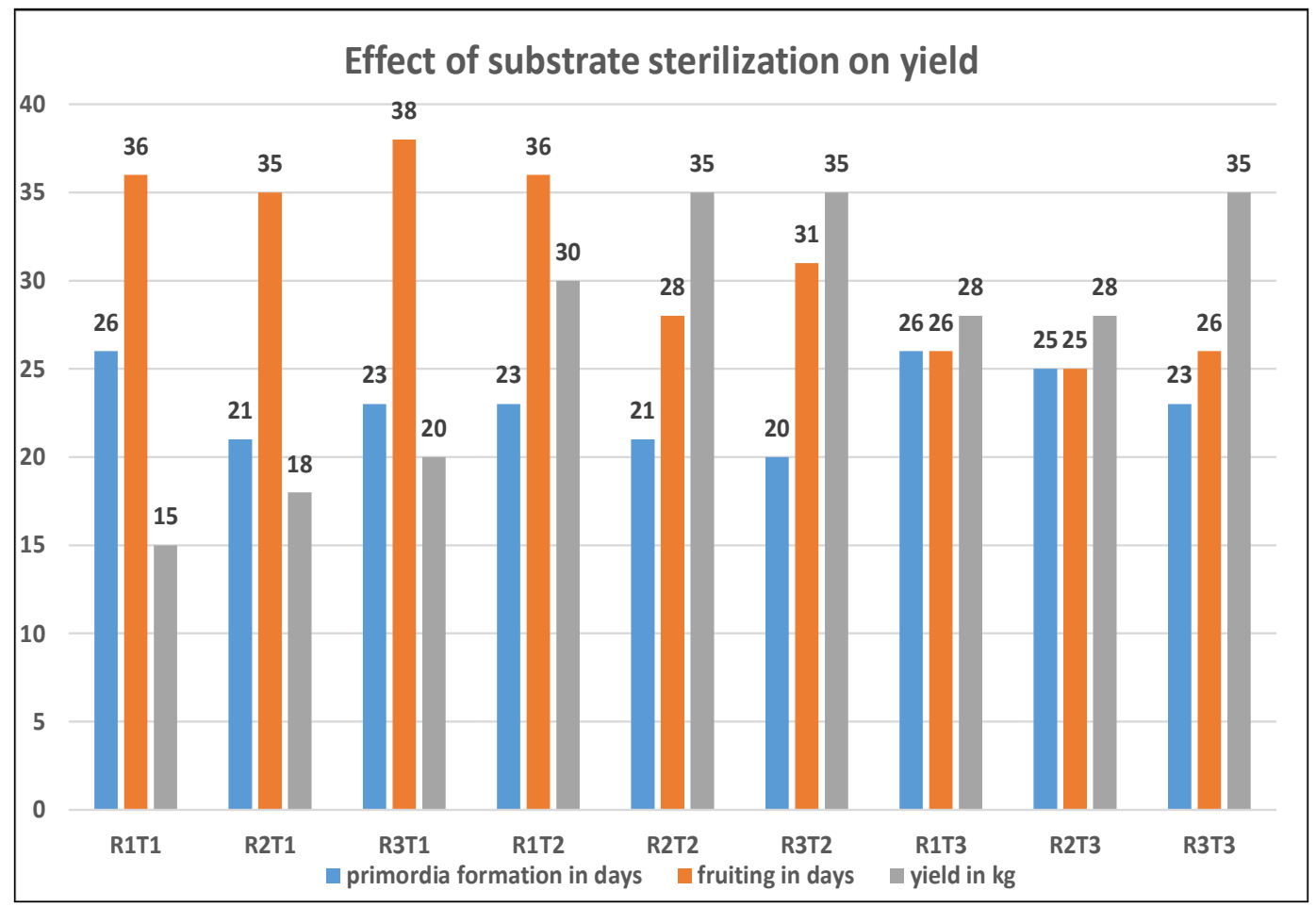

Fig 1: Bar graph showing effect of sterilization technique in context of primordia formation, fruiting and yield. 


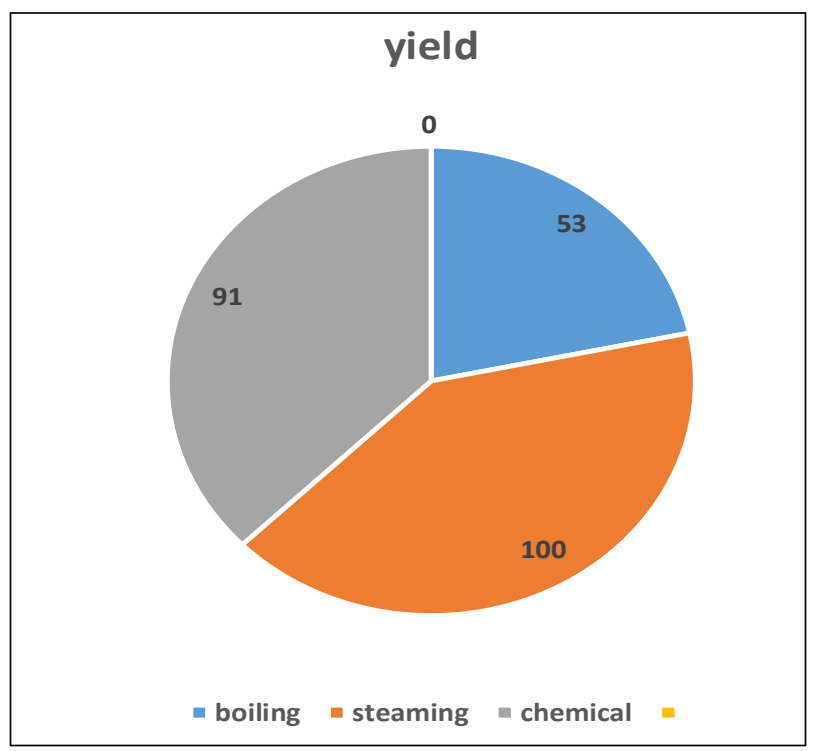

Fig 2: Pie chart showing yield obtained from different methods of sterilization of substrate.

\section{Substrate sterilization techniques}

\section{Boiling method}

The paddy straw was chopped and it was soaked into cold water for $4 \mathrm{hrs}$. in galvanized iron drum and excess water was drained and fresh water was added and the sample was boiled over a flame for an hour. The water content was checked by hand feel method and the $\mathrm{n}$ filled in the polybag of size $16^{*} 16$ inches. In the research it is indicated by T1.

\section{Steaming method}

The paddy was chopped and the chopped straw particles were then soaked in cold liquid for four hours in GI drum. The chopped straw was filled in jute bag and with the help of tripod stand, the straw piece was heated. In the research it is indicated by $\mathrm{T} 2$.

\section{Chemical method}

For $10 \mathrm{~kg}$ of straw $10 \mathrm{gm}$. of carbendazin $120 \mathrm{ml}$ of formalin, and $15 \mathrm{gm}$. of agriculture lime was used and the cleaned straw was treated with 100 litres of water along with the chemicals. After $16 \mathrm{hrs}$, the excess water is drained and the sample was filled in polybag. In the research it is indicated by T3.

\section{Harvesting, collection and statistical analysis}

After the maturation of the mushroom and obtaining of the appropriate size, it was harvested using the sterilized knife. The days concerning to the period of Primordia formation and fruit instigation, fresh weight of collected mushroom at first and second flushes and third flushes were taken. All the collected data were tabulated according to categorical and continuous variables. Initially the recorded data was entered using Microsoft Excel 2016. All the figures and graphs were prepared in Microsoft Excel 2016. Manuscript was prepared by using Microsoft word 2016.

\section{RESULTS AND DISCUSSION}

The research conducted in the laboratory condition shows that Primordia formation is higher in chemical method followed by steaming method and boiling method as in Fig 1. In similar manner, fruiting is initiated and obtained earlier in chemical method and later in boiling method. Yield can be obtained higher in steaming method followed by chemical method and boiling method.

The Fig 2 shows that higher yield can be obtained from steaming method. From the result it can be understand that for the higher yield and commercialization of the oyster mushroom the steaming method should be followed and for early primordial formation chemical method is favorable.

\section{CONCLUSION}

From the research, individual can conclude that for the earlier yielding of oyster mushroom, chemical method can be followed but for the higher yield and commercial purposes of mushroom production, if the steaming method is followed individual can ensure profit for long run as well. But even though this research is not final enough to indicate that steaming method is best for commercial point of view. Further more research are needed to be conducted for higher efficiency.

\section{Conflict of interest}

The biographer avowed no conflict of attention.

\section{ACKNOWLEDGEMENT}

The author provides mammoth gratitude towards the assisting hands including friends, family members and participants throughout the period of data collection.

\section{REFERENCES}

Carluccio, A. (1989). A Passion for Mushrooms. London: Pavillion Books Ltd.

Chang, S.T. (1992). Cultivation of Volvariella Mushrooms in Southeast Asia, In: Trop. Mushrooms. Biological Nature and Cultivation Methods, (The Chinese Univ. Press). 135-156.

Gupta, R.S. (1986). Mushroom Cultivation. Indian Hort. 31(1): 11. Kong, W. (2004). Oyster Mushroom Cultivation (Descriptions of Commercially Important Pleurotus species). Mushworld.

Mondal, S.R., Rehana, M.J., Noman, M.S. and Adhikary, S.K. (2010). Comparative study on growth and yield performance of oyster mushroom (Pleurotus florida) on different substrates. Journal of Bangladesh Agricultural Univeristy. 8(2): 213-220.

Mori, K., Toyomasu, T., Nanba, H. and Kuroda, H. (1986). Antitumor Activities of Edible Mushrooms By Oral Administration. Proc. Int'l. Sym. Sci. Tech. Aspect of Culti. Edible Fungi. (Penna. State Univ. USA.), 49-55. 
Nadir, H.A., Ali, A.J. and Muhammed, G.A. (2016). Determination of yield and quality of oyster mushroom (Pleurotus florida) using different substrates in Halabja, Kurdistan. Plant Production. 7: 787-790.

Randive, S. (2012). Cultivation and study of growth of oyster mushroom on different Agricultural Waste Substrate and Its Nutrient Analysis. Advances in Applied Science Research. 3(4): 1938-1949.
Song, B.C. (2004). Oyster Mushroom Cultivation Mushroom Growers Handbook.

Stamets, P. (1990). A discussion on the cultivation of Ganoderma lucidum (curtis:Fr.) kar. The reishi of ling zhi mushroom of mortality. Mcllvainea. 9(2): 40-50.

Kong. n.d, W. Oyster Mushroom Cultivation Descriptions of Mushworld. Willard, T. (1990). Reishi Mushroom. Herb of spiritual potency and medical wonder (Sylvan press, Issaquah, W.A.). 238-249. 